\title{
Appraisal of $\varepsilon$-Caprolactam and Trimellitic Anhydride Potential Novel Chain Extenders for Poly(lactic acid)
}

\author{
Imane Mayouf ${ }^{(1)},{ }^{1}$ Melia Guessoum, ${ }^{1}$ Mónica Fuensanta, ${ }^{2}$ José Miguel Martín Martìnez ${ }^{2}$ \\ ${ }^{1}$ Laboratoire de Physico-Chimie des Hauts Polymères (LPCHP), Département de Génie des Procédés, Faculté de \\ Technologie, Université Ferhat ABBAS Sétif-1, Sétif, Algeria \\ ${ }^{2}$ Adhesion and Adhesives Laboratory, University of Alicante, 03080, Alicante, Spain
}

\begin{abstract}
The potential of $\varepsilon$-caprolactam (CAP) and trimellitic anhydride (TMA) compounds as novel chain extenders for poly(lactic acid) (PLA) has been assessed; the amounts of $0.01,0.025$, and 0.05 wt $\%$ each additive have been added. The chain extension was evidenced by the increase in PLA/CAP and PLA/TMA viscosities in mixing torque measurements and by infrared spectroscopy. PLA reaction with CAP and TMA has also been confirmed from contact angle and surface free energy studies, which have shown that the increase in TMA amount decreased the hydrophilicity of PLA due to the decreased concentration of terminal surface hydroxyl groups. However, the addition of CAP accentuated the PLA hydrophilicity as indicated by the increase in the polar component of the surface energy. On the other hand, the glass transition temperature of PLA/TMA and PLA/CAP decreased as a result of a local plasticizing effect, which favored the chain mobility and the crystallization of PLA due to the concomitant nucleating effect of the chain extenders moieties too. Furthermore, the higher molecular weight of PLA/CAP and PLA/TMA was responsible for their increased thermal stability and higher impact strength with respect to PLA. POLYM. ENG. SCI., 00:000-000, 2020. () 2020 Society of Plastics Engineers
\end{abstract}

\section{INTRODUCTION}

Poly(lactic acid) (PLA) is a linear aliphatic thermoplastic presenting a wide range of physical and mechanical properties, being the most commonly used polymer in the bioplastics industry [1, 2]. Technically, PLA shows similar properties to those of polystyrene and poly(ethylene terephthalate) (PET) [3]. Currently, PLA research aims to make the polymer an adequate replacement for commodity synthetic polymers in many applications including food and textile industries [4, 5].

Despite its advantages, PLA shows some limitations that make it unsuitable for some applications, thus restricting its utilization [2]. PLA suffers from poor thermal stability, low mechanical resistance, and inherent brittleness, which prevent its use in applications demanding high mechanical performances [3, 5, 6]. In addition to water sensitivity [4], another PLA shortcoming is its limited gas barrier property, which precludes its suitable use as industrial packaging material [6]. Also, compared to conventional polymers, PLA presents a relatively low melt strength, which is a critical limitation for its processing by thermoforming, blowing, and foaming [7]. To remedy PLA deficiencies, various strategies such as blending [8], reinforcing by mineral and cellulosic fillers

Correspondence to: I. MAYOUF; e-mail: imen_myo@yahoo.fr DOI 10.1002/pen.25350

Published online in Wiley Online Library (wileyonlinelibrary.com).

(C) 2020 Society of Plastics Engineers
[9], copolymerization [10], and plasticization [11] have been proposed and found to induce beneficial changes particularly on mechanical, thermal, and rheological properties.

Furthermore, PLA undergoes thermal degradation resulting in premature scission of polymer chains due to inter- and/or intramolecular transesterification reactions. The ensuing serious decrease in viscosity is also substantiated by a decline in the melt strength of the polymer, thus leading to poor mechanical properties. The severity of premature scission of PLA chains is tightly related to the processing conditions and the presence of lowmolecular-weight impurities, such as monomer residues and catalyst during synthesis $[1,12,13]$.

To improve PLA rheology, an increase of its molecular weight and its melt strength should enlarge its processing window. So, the use of chain extenders seems an adequate strategy. Chain extenders have been developed to improve the melt strength and thermal stability as well as they act as good compatibilizers in polymer blends [7]. Chain extenders allow an increase of the molecular weight by inter-connecting polymer chains and relinking the chain fragments, thus attenuating the effects of degradation reactions occurring during processing. In polycondensates, the chain extension is achieved by reacting the polymers end groups with bi- or multi-functional reactive moieties such as epoxy, diisocyanate, dianhydride, and diamine groups [14, 15]. In the case of PLA, the chain extender can generally react with terminal carboxyl and hydroxyl groups and improves its processing performances when melt strength is crucial [6, 14, 16-18].

Several recent studies have demonstrated the feasibility of the PLA chain extending. Liu et al. [18] examined the properties of PLA modified with an epoxy chain extender. The chain extension of PLA via the reaction between the epoxy and carboxyl groups was evidenced by the decrease in the melt flow index (MFI) from 6 to $0.11 \mathrm{~g} / 10 \mathrm{~min}$ and the crystallinity from $17 \%$ to $13.2 \%$. However, the impact strength increased from 16.58 to $23.12 \mathrm{~kJ} \mathrm{~m}^{-2}$ and the Vicat softening temperature was enhanced from $67.9^{\circ} \mathrm{C}$ in neat PLA to $160.1{ }^{\circ} \mathrm{C}$ when $1 \mathrm{wt} \%$ of the chain extender was added. Furthermore, Jaszkiewicz et al. [12] studied the effects of two chain extenders (Joncryl ADR 4368S and Joncryl ADR 3229) containing, respectively, epoxy and maleic anhydride functionalities, on the properties and processability of two grades of PLAs with different molecular weights and reactivities. In opposite to Joncryl ADR 3229 which maleic anhydride functional groups showed a poor reactivity toward PLA carboxyl and hydroxyl terminal groups, Joncryl ADR 4368S allowed a noticeable improvement of the shear viscosity resulting in an increase of the molecular weight due to the reaction of the epoxy groups with the PLA end groups. Additionally, Jaszkiewicz et al. [16] showed that the free ends of the polymer chains reacted with the epoxide groups, which decreased the stress concentrations and 
reduced the extent of the crack initiation and propagation. However, they observed that the stiffness remained unaffected. The increase of the elastic modulus resulted from a reduced number of short-chains, which were transformed by the epoxidized chain extender to long-chain structures. In addition, they proposed that the apparent spread of plastic fracture zones was directly related to the achievable average molecular mass and emerging branches. Rathi et al. [19] quantified the efficiency of several epoxyfunctional reactive oligomers and stated the molecular weight enhancement with the increase in the functionality of the chain extenders. They also observed that no gelation occurred due to the preferential reaction of the epoxy groups with the carboxylic acid and the negligible reactivity of the hydroxyl groups at the ends of the degraded PLA chains. Iñiguez-Franco et al. [20] showed that the addition of $1.5 \mathrm{wt} \%$ of an epoxy chain extender enabled an increase of PLA thermal stability and contributed to decreasing its hydrolytic degradation.

Besides, Najafi et al. [21] found that the epoxy chain extender and the processing conditions contributed to attaining a good dispersion of nanoclay platelets in PLA nanocomposites and in increasing significantly their modulus and toughness. RamirezHerrera et al. [22] studied the structural, thermal, and mechanical properties of PLA modified with three different chain extenders (1,3-phenylene-bis-2-oxazoline [PBO], pyromellitic dianhydride [PMDA], and 1,10-carbonyl bis caprolactam [CBC]). PBO, PMDA, and $\mathrm{CBC}$ chain extenders were added at three concentrations during the three stages of PLA processing, that is, monomer dehydration, oligomer polycondensation, and melt polycondensation. Even though the slight structural modifications, the PLA glass transition, and crystallinity decreased, the mechanical properties, hardness, elastic modulus, and indentation creep increased due to chain extension. The thermal and structural characterization revealed also that the PLA/PBO, PLA/PMDA, and PLA/CBC polymers were more resistant than neat PLA to UV light and humidity during accelerated weathering tests. Buccella et al. [23] evaluated the chain extension ability of $\mathrm{CBC}$ by melt compounding a commercial polyamide 6 (PA6) and they observed that the PA6 viscosity, crystallinity, and melting temperature increased with the chain extender amount. While the elastic and yield properties of the chain extended PA6 were similar to those of neat PA6, the chain extension was responsible for an increase in the elongation-at-break values. In previous study, Gouissem et al. [24] studied the combined effect of heat treatment and the addition of small amounts of two chain extenders based on cyclic amid and anhydride functionalities $-\varepsilon$-caprolactam (CAP) and trimellitic anhydride (TMA) — on the properties of recycled PET. They found that this combination was very promising since extruded mixtures exhibited quite acceptable rheological properties and a noticeably improved resistance against hydrolytic degradation.

In this work, CAP and TMA were used as effective chain extenders for PLA. Evidence of PLA chain extension could be acquired from viscosity variations estimated from the changes in PLA/CAP and PLA/TMA mixtures mixing torque and by surface characterization with infrared attenuated total reflectance spectroscopy and contact angle measurements. Thereafter, the properties of the chain extended PLAs were assessed as a function of the nature and amount of the chain extender, and the mechanical, thermal, and morphological properties were evaluated by using several experimental techniques including impact resistance measurements, differential scanning calorimetry (DSC), dynamic mechanical thermal analysis (DMTA), thermal gravimetric analysis, and scanning electron microscopy.

\section{EXPERIMENTAL}

\section{Materials}

PLA derived from vegetal resources (PLI 005 resin) was supplied by Nature Plast-Caen, France. Some of its characteristics are MFI at $190^{\circ} \mathrm{C}$ and under $2.16 \mathrm{~kg}$ : $10-30 \mathrm{~g} / 10 \mathrm{~min}$; melting temperature: $145^{\circ} \mathrm{C}-155^{\circ} \mathrm{C}$; and degradation temperature: $240^{\circ} \mathrm{C}-$ $250^{\circ} \mathrm{C}$. CAP-azepan-2-one-with purity of about $98 \%$ and molecular weight of $113.16 \mathrm{~g} \mathrm{~mol}^{-1}$ was supplied by Fluka, Darmstadt, Germany. TMA (1,3-dioxo-2-benzofuran-5-carboxylic acid) with purity higher than $97 \%$ and molecular weight of $192.13 \mathrm{~g} \mathrm{~mol}^{-1}$ was supplied by Fluka, Darmstadt, Germany.

\section{PLA/CAP and PLA/TMA Mixtures Preparation}

CAP and TMA chains extenders, and PLA were dried at $40^{\circ} \mathrm{C}$ and $60^{\circ} \mathrm{C}$ for $24 \mathrm{~h}$, respectively. PLA/CAP and PLA/TMA mixtures were prepared with $0.01,0.025$, and $0.05 \mathrm{wt} \% \mathrm{CAP}$ or TMA by melt mixing at $180^{\circ} \mathrm{C}$ and $45 \mathrm{rpm}$ for $30 \mathrm{~min}$ in a Brabender plasticorder ${ }^{\circledR}$ equipment (Duisburg, Germany). The addition of CAP and TMA was carried out after $3 \mathrm{~min}$ of processing.

\section{Experimental techniques}

Rheological and Viscoelastic Properties. Determination of the viscosity. The viscosities of PLA/CAP and PLA/TMA mixtures were assessed from the variations of the torque versus time during melt mixing in the internal mixer.

Dynamic mechanical thermal analysis. The viscoelastic properties were measured in DMA-Q800 equipment (TA Instruments, New Castle, DE) in single cantilever geometry. Neat PLA, PLA/CAP, and PLA/TMA samples with dimensions $\left(18 \times 10 \times 2 \mathrm{~mm}^{3}\right)$ were heated from $35^{\circ} \mathrm{C}$ to $150^{\circ} \mathrm{C}$ at a heating rate of $5^{\circ} \mathrm{C} \mathrm{min}{ }^{-1}$. All experiments were carried out at a frequency of $1 \mathrm{~Hz}$, an amplitude of $20 \mu \mathrm{m}$, and a strain of $0.5 \%$.

Structural Analysis. Infrared spectroscopy. The chemical structures of neat PLA, CAP, and TMA in addition to PLA/CAP and PLA/TMA were assessed by attenuated total reflectance-Fourier-transform infrared spectroscopy (ATR-FTIR) in an Alpha spectrometer (Bruker Optik GmbH, Ettlinger, Germany) using a germanium prism. Sixty scans were recorded and averaged at a resolution of $4 \mathrm{~cm}^{-1}$ in the wavenumber range $4,000-400 \mathrm{~cm}^{-1}$. Under these experimental conditions, a depth of the surface of about $1 \mu \mathrm{m}$ was analyzed.

Contact angle measurements. Contact angle measurements were performed at $20^{\circ} \mathrm{C}$ by using a polar liquid (bi-distilled and deionized water) and a non-polar liquid (diiodomethane). The contact angles were measured on the surface of neat PLA, PLA/CAP, and PLA/TMA in an ILMS goniometer (GBX Instruments, Bourg-de-Pèage, France). A drop of water or diiodomethane was placed on the surface and the contact angle was evaluated $5 \mathrm{~min}$ after drop deposition. The contact angle values were calculated as the average of the angles obtained with three drops placed in 
different areas of the film's surface. The surface energies $\left(\gamma_{s}\right)$ of the neat PLA, PLA/CAP, and PLA/TMA were determined from the water and diiodomethane contact angle values by using the Owens-Wendt approach (Eq. 1):

$$
\frac{\left(1+\cos \theta_{i}\right) \gamma_{l i}}{\sqrt{\gamma_{l i}^{d}}}=\sqrt{\gamma_{s}^{p}}+\sqrt{\frac{\gamma_{l i}^{p}}{\gamma_{l i}^{d}}} \sqrt{\gamma_{s}^{d}}
$$

where $\gamma_{s}^{p}$ and $\gamma_{s}^{d}$ are, respectively, the polar and dispersive components of the surface energy, $\theta_{i}$ is the contact angle measured with each test liquid, and $\gamma_{l i}^{p}$ and $\gamma_{l i}^{d}$ are the polar and dispersive components of the surface tension of water and diiodomethane test liquids.

Differential scanning calorimetry. The glass transition and crystallization of neat PLA, PLA/CAP, and PLA/TMA were determined by DSC in Q100 DSC equipment (TA Instruments). The experiments were carried out under nitrogen atmosphere (flow rate: $50 \mathrm{~mL} \mathrm{~min}{ }^{-1}$ ). About $8-9 \mathrm{mg}$ of samples were placed in an aluminum hermetic pan and heated from $0^{\circ} \mathrm{C}$ to $200^{\circ} \mathrm{C}$. Afterward, the sample was cooled down to $0^{\circ} \mathrm{C}$ and then heated again to $250^{\circ} \mathrm{C}$. The cooling and heating rates were $10^{\circ} \mathrm{C} \mathrm{min}{ }^{-1}$. The glass transition temperature $\left(T_{g}\right)$, melting temperature $\left(T_{m}\right)$, and melting enthalpy $\left(\Delta H_{m}\right)$ were evaluated from the second DSC heating run, while the crystallization temperature $\left(T_{c}\right)$ and enthalpy $\left(\Delta H_{c}\right)$ were determined from the DSC cooling run. The degree of crystallinity $\left(\chi_{c}\right)$ of PLA, PLA/CAP, and PLA/TMA was evaluated according to Eq. 2:

$$
\chi_{c}(\%)=\frac{\Delta H}{\Delta H_{m}^{0}\left(1-\omega_{\mathrm{ce}} \%\right)} \times 100
$$

where $\Delta H$ corresponds to $\Delta H_{c}$ and $\Delta H_{m}$ of the samples obtained from the DSC cooling and second heating run, respectively, and $\omega_{\text {ce }} \%$ is the fraction of the chain extender. The melting enthalpy of the fully crystallized PLA $\left(\Delta H_{m}^{0}\right)$ is $93 \mathrm{~J} \mathrm{~g}^{-1}$ [13].

$X$-ray diffraction. The microstructures of the neat PLA, PLA/CAP, and PLA/TMA were determined by X-ray diffraction (XRD) in a Bruker D8-Advance diffractometer (Bruker, Ettlingen, Germany) using a copper cathode and a nickel filter with Göbel mirror. The wavelength of $\mathrm{Cu} \mathrm{k} \alpha$ radiation $(\lambda)$ was 0.1540598 $\mathrm{nm}$. XRD patterns of the samples were recorded at room temperature at $2 \theta$ values from $5^{\circ}$ to $30^{\circ}$ with a step size of $0.05^{\circ}$ acquired at a scan rate of $3 \% \mathrm{~min}$. The crystallites size $(L)$ was calculated using Scherrer's equation (Eq. 3):

$$
L=\frac{0.9 \lambda}{\beta \cos \theta}
$$

where $\beta$ and $\theta$ are the breadth at half-maximum intensity and the Bragg angle, respectively.

Thermal gravimetric analysis. The thermal stabilities of the neat PLA, PLA/CAP, and PLA/TMA were determined in TGA Q500 equipment (TA Instruments) under the nitrogen atmosphere (flow rate: $50 \mathrm{~mL} \mathrm{~min}^{-1}$ ). About $10-11 \mathrm{mg}$ of samples were placed in a platinum crucible and then heated from $25^{\circ} \mathrm{C}$ to $600^{\circ} \mathrm{C}$ at a heating rate of $10^{\circ} \mathrm{C} \mathrm{min}^{-1}$. The degradation parameters, including the temperatures at which starts $\left(T_{\mathrm{d} 0}\right)$ and finishes the decomposition $\left(T_{\mathrm{fd}}\right)$, the temperature at maximum weight loss $\left(T_{\mathrm{dmax}}\right)$, the temperatures corresponding to the weight loss of $5 \%$ $\left(T_{5 \%}\right)$ and $50 \%\left(T_{50 \%}\right)$, and the decomposition rate $\left(V_{\mathrm{d}}\right)$ were evaluated.

Morphological Analysis by Scanning Electron Microscopy. The morphologies of neat PLA, PLA/CAP, and PLA/TMA were assessed in a Hitachi S-3000N (Hitachi Ltd., Tokyo, Japan) scanning electron microscope and an electron beam energy of $15 \mathrm{kV}$ was used. Morphology observations were done on Izod impact fractured surfaces and for improving the contrast, the surfaces were gold coated in a Balzers SCD 004 sputtering unit (Oerlikon Balzers, Liechtenstein).

Mechanical Properties Izod Impact Test. Unnotched specimens with dimensions $\left(63 \times 13 \times 2 \mathrm{~mm}^{3}\right)$ were subjected to Izod impact test at room temperature in a Resil impact pendulum (Ceast, Italy), consisting basically of a heavy pendulum equipped with a hammer of $7.5 \mathrm{~J}$ inclined by a fingernail of $150^{\circ}$, and a dial indicating the energy absorbed during the impact $\left(A_{n}\right)$. The impact strength $\left(a_{n}\right)$ of the samples was calculated using the following equation

$$
a_{n}=\frac{A_{n}}{b \times e}
$$

where $b$ and $e$ are the width and the thickness of the test specimens, respectively.

\section{RESULTS AND DISCUSSION}

\section{Rheological Properties of PLA/CAP and PLA/TMA}

To examine the effects of the addition of CAP and TMA chain extenders on the rheological properties of PLA, torque-time curves recorded during the mixing of PLA/CAP and PLA/TMA are displayed in Fig. 1 and 1. The initial torque is generally high due to the solid-state of the granules and, after melting, the torque decreases with time due to a decrease of the viscosity because of the removal of the interactions between the polymeric chain, until the torque value is somewhat constant.

The rheogram of the neat PLA shows that after $30 \mathrm{~min}$ of processing, the mixing torque is $2.27 \mathrm{~N} \mathrm{~m}$ and by adding 0.01 , 0.025 , and $0.05 \mathrm{wt} \% \mathrm{CAP}$, the mixing torque increased noticeably as compared to neat PLA, reaching 2.99, 2.97, and $2.77 \mathrm{~N} \mathrm{~m}$, which is equivalent to improvements of $32 \%, 31 \%$, and $22 \%$, respectively (Fig. 1a). The increase in the CAP amount decreases the torque value after $30 \mathrm{~min}$ of mixing, indicating a plasticizing effect when its amount increases. The same trend is revealed in PLA/TMA (Fig. 1b), the torque values are 2.41, 2.99, and $3.27 \mathrm{~N}$ $\mathrm{m}$ when $0.01,0.025$, and $0.05 \mathrm{wt} \%$ TMA are added to PLA, respectively - an increase by $6 \%, 31 \%$, and $44 \%$ by adding 0.01 , 0.025 , and $0.05 \mathrm{wt} \%$ TMA, respectively. The different behaviors in the torque values of the chain extended polymers have been previously reported. Thus, Arruda et al. [7] studied PLA and poly(butylene adipate-co-terephthalate) (PBAT) chain extension with Joncryl ADR 4368 and they found an increase in torque of $19 \%$ and $23 \%$ by adding $0.3 \%$ and $0.6 \%$ chain extender to PBAT, whereas the chain extended PLA exhibited higher reactivity and 

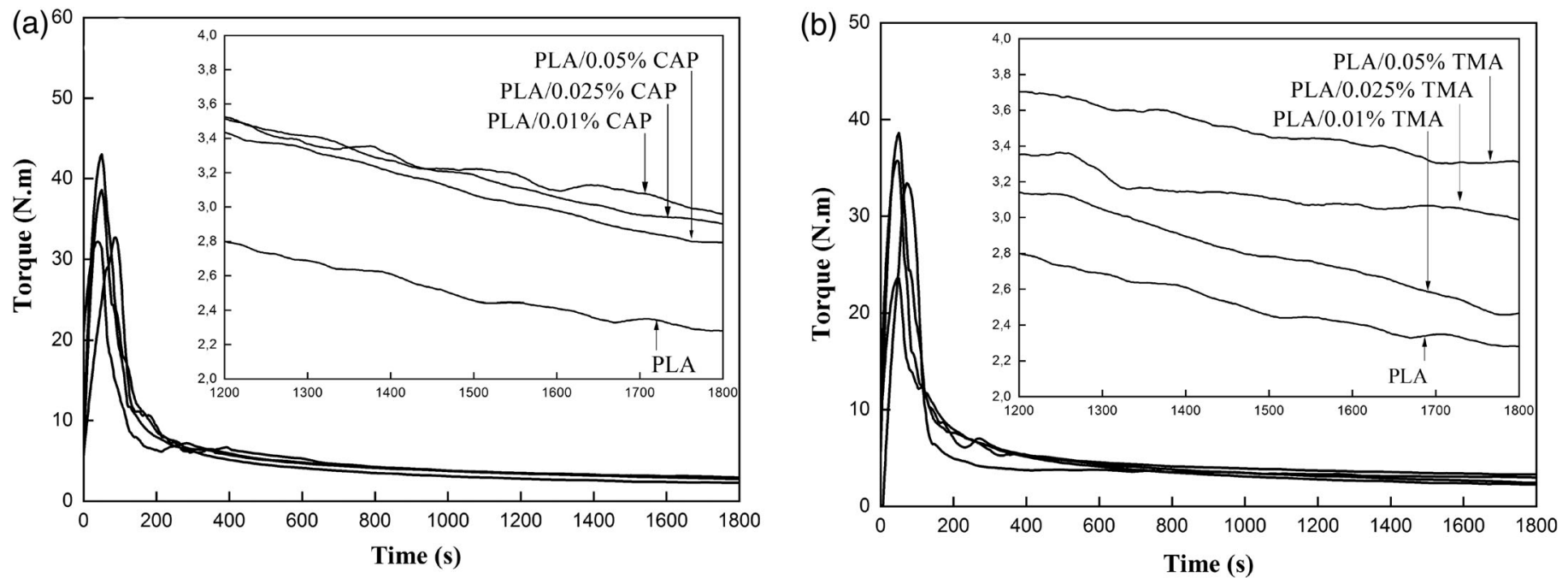

FIG. 1. Variation of the mixing torque for (a) PLA/CAP and (b) PLA/TMA mixtures versus time.

the torque enhancements were by $36 \%$ and $59 \%$, respectively. Furthermore, Meng et al. [25] assessed the chain extending of triphenylphosphite and concluded an optimal efficiency for a concentration of 3\%. Gouissem et al. [24] used TMA and CAP chain extenders for recycled PET and showed that the addition of small concentrations of CAP and TMA allows the decrease in the MFI of PET, which corresponds to an increase in the polymer molecular weight and viscosity.

Under temperature, shear and catalysts residues, PLA may suffer chain scissions, which could induce a persistent decrease in the torque values during its processing. However, the above experimental results suggest that by adding CAP or TMA chain extenders, the effects of the degrading reactions could be counteracted through reconnecting the functional polymer chains ends via chemical reactions with the chain extenders. Figure $2 \mathrm{a}$ displays the potential chemical reactions responsible for PLA upgrading by using CAP. Due to the great structural similarities between $\mathrm{CAP}$ and $\mathrm{CBC}$, the mechanism of the chain extension of PLA with CAP can be the same proposed as by Ramirez-Herrera et al. [22] and Buccella et al. [23] for CBC. The mechanism involves the nucleophilic attack of the terminal hydroxyl group $(\mathrm{OH})$ either at the central carbonyl group or at the carbonyl of the rings of the caprolactam, and intermediate reactions occur forming carbonates, urethane, and urea [22]. Also, Buccella et al. [23] reported that the nucleophilic substitution is possible at low temperatures, while at higher temperatures the caprolactam ring opening is more likely to occur.

In the case of TMA, the torque increase could be explained by the occurrence of two sorts of processes involving coupling and branching reactions. The coupling reaction takes place when the anhydride function of TMA interacts with the terminal hydroxyl groups of two PLA chains, giving two carbonyl groups. The branching reaction occurs when more than two PLA chains react with one TMA molecule. Accordingly, Ramirez-Herrera et al. [22] also reported a complex branching reaction that generated a crosslinked structure or gel when $1 \mathrm{wt} \%$ PMDA was incorporated into PLA. In this sense, the TMA molecule acts as a bifunctional chain extender since it behaves like a bridge between two PLA chains or fragments and induces an increase in the PLA viscosity, as it is shown in the scheme of Fig. 2b. This mechanism identical to that proposed by Xanthos et al. [26], Awaja et al. [27], and Ramirez-Herrera et al. [22] for PMDA concerns the reaction of one TMA moiety with two PLA chains, thus causing the increase in the molecular weight. Concomitantly, the involvement of a third PLA chain results in chain branching and in the change of the molecular weight distribution. The increase of the molecular weight in the chain extended PLA can be indirectly confirmed by the increase of the values of the storage moduli at low temperature in DMTA plots (Figs. 3 and Fig. 4).

The viscoelastic behavior of PLA, PLA/CAP, and PLA/TMA was studied by DMTA and the variations of the storage modulus $\left(E^{\prime}\right)$ and the damping factor $(\tan \delta$ ) as a function of the temperature are shown in Figs. 3 and Fig. 4, respectively. Along the glassy region, the neat PLA exhibits a steady storage modulus of 5,156 $\mathrm{MPa}$. As the glass transition approaches, the storage modulus tends to decrease gradually by increasing the temperature and shows a remarkable decrease at $86^{\circ} \mathrm{C}$, which corresponds to the PLA glass transition temperature, which is better evidenced in the maximum observed in the variations of $\tan \delta$ versus temperature. This $T_{g}$ value of PLA measured with DMTA differs from the one measured with DSC (see below) due to the fact that the glass transition of the polymers depends on the measurement method $[28,29]$. The increase of the temperature decreases the storage modulus due to the softening of PLA because of the increase in the PLA chains mobility.

In the glassy region, the addition of CAP or TMA increases the storage modulus of PLA due to higher interactions between the polymer chains. However, after the glass transition, the addition of 0.01 and $0.05 \mathrm{wt} \%$ TMA or CAP causes a slight decrease in the storage modulus of PLA, thus emphasizing a reduction in the polymer stiffness; nevertheless, the PLA stiffness increases in PLA/0.025 wt\% TMA and PLA/0.025 wt\% CAP. On the other hand, PLA/CAP displays somewhat broader $\tan \delta$ plots and the values of the maxima $\tan \delta$ are similar to that for neat PLA (Table 1). Because the $T_{g}$ value of PLA/0.05 wt $\%$ CAP is lower $\left(82^{\circ} \mathrm{C}\right)$ than for PLA, the mobility of the amorphous region in PLA/0.05 wt $\%$ CAP is favored as compared to that in the neat PLA, which seems to impart a local 
<smiles>NCCCCCC(=O)OC(=O)OCc1ccccc1</smiles>

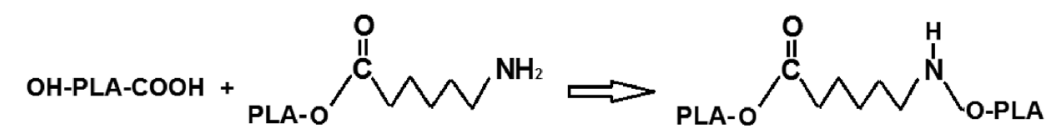<smiles>O=C(O)C(OC(=O)[C@@H](O)C(=O)O)C(=O)O</smiles><smiles>O=C(O)C(=O)O[Hg]O[C@H](C(=O)O)C(=O)OC(=O)c1ccc(C(=O)O)cc1C(=O)O</smiles>

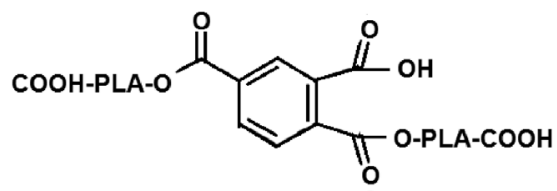

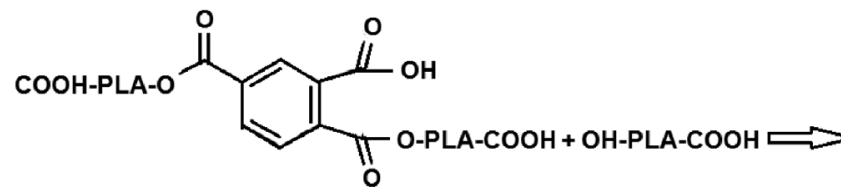<smiles>CC(=O)O[14C](=O)OC(=O)OC(=O)c1ccc(C(=O)OC(=O)OCc2ccccc2)c(C(=O)O)c1</smiles>

FIG. 2. Scheme of: (a) $\varepsilon$-caprolactam ring-opening mechanism and possible interaction with PLA end groups, (b) possible mechanism of PLA chain extension with trimellitic anhydride.

plasticizing effect; this fits well with the Izod impact resistance results (see below).

However, PLA/TMA reveals different behavior with respect to PLA/CAP. PLA/TMA formulations with 0.025 and $0.05 \mathrm{wt} \%$ TMA exhibit lower $\tan \delta$ values than the neat PLA (Table 1) and, therefore, as the TMA concentration increases, more restrictions are imposed to the PLA chains mobility, and that the more PLA chains extension occurs, more aromatic rings of TMA are integrated into the PLA chains. Meanwhile, the insertion of more aromatic rings into the PLA chains will increase its free volume and will decrease its packing, all contributing to increased stiffness.

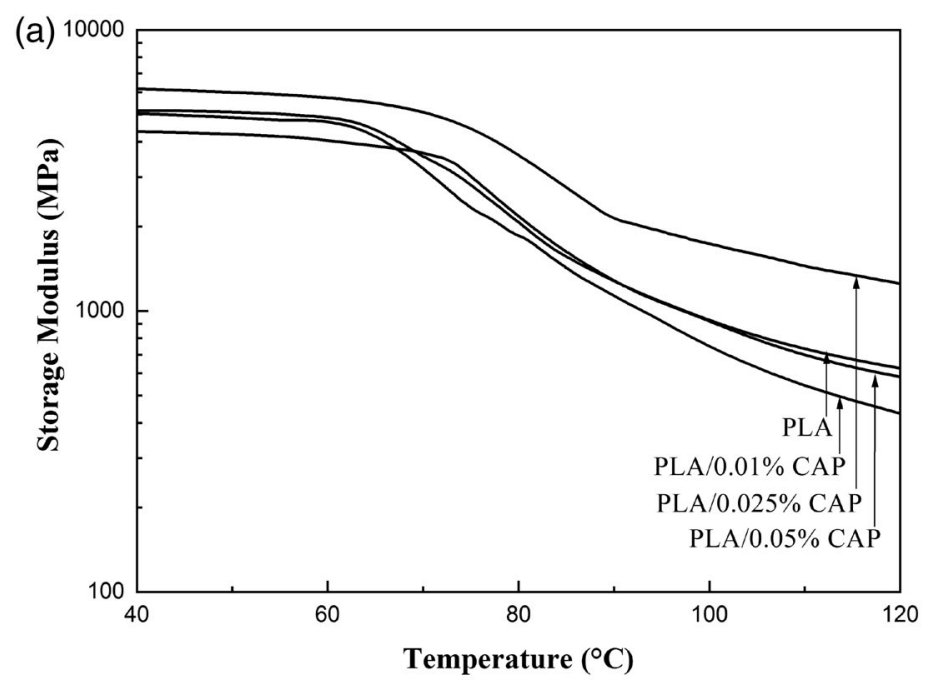

On the other hand, the $T_{g}$ value of PLA $/ 0.05 \mathrm{wt} \% \mathrm{TMA}\left(79^{\circ} \mathrm{C}\right)$ is lower than in PLA due to the dominant increase of the free volume of the polymer chains over the interactions between TMA and the chains. Furthermore, the values of $\tan \delta$ are higher in PLA/CAP than in PLA/TMA, indicating different effects of the chain extender on the viscoelastic properties of PLA. Conclusively, the viscoelastic behavior of PLA after extension with both CAP and TMA is complex because of the concomitant interference of various parameters including the structure of the chain extender, the fraction of free volume, and the entanglements between the chains.

FIG. 3. Variation of: (a) the storage modulus and (b) $\tan \delta$ as a function of temperature for neat PLA and PLA/CAP.

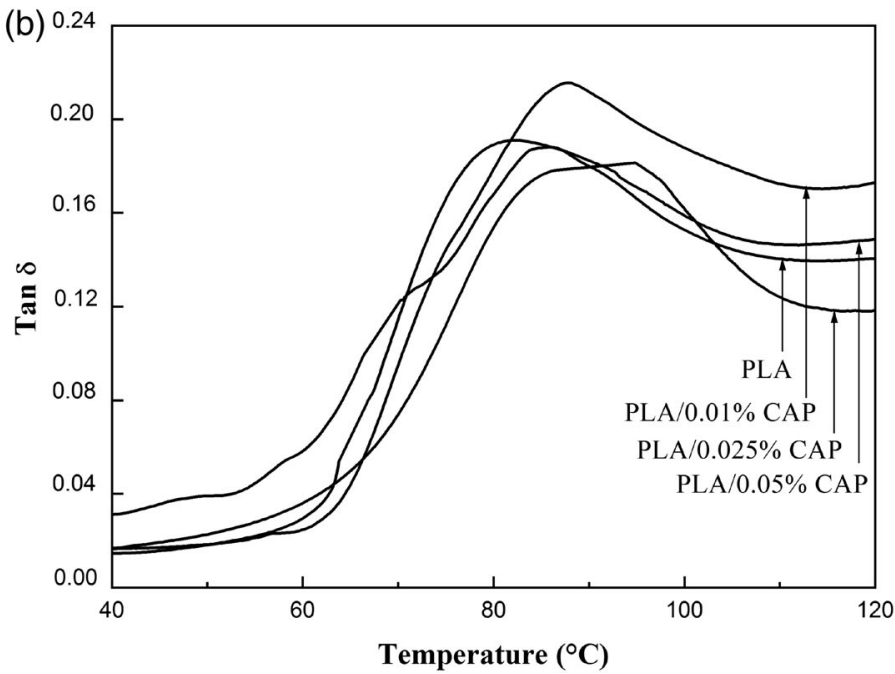



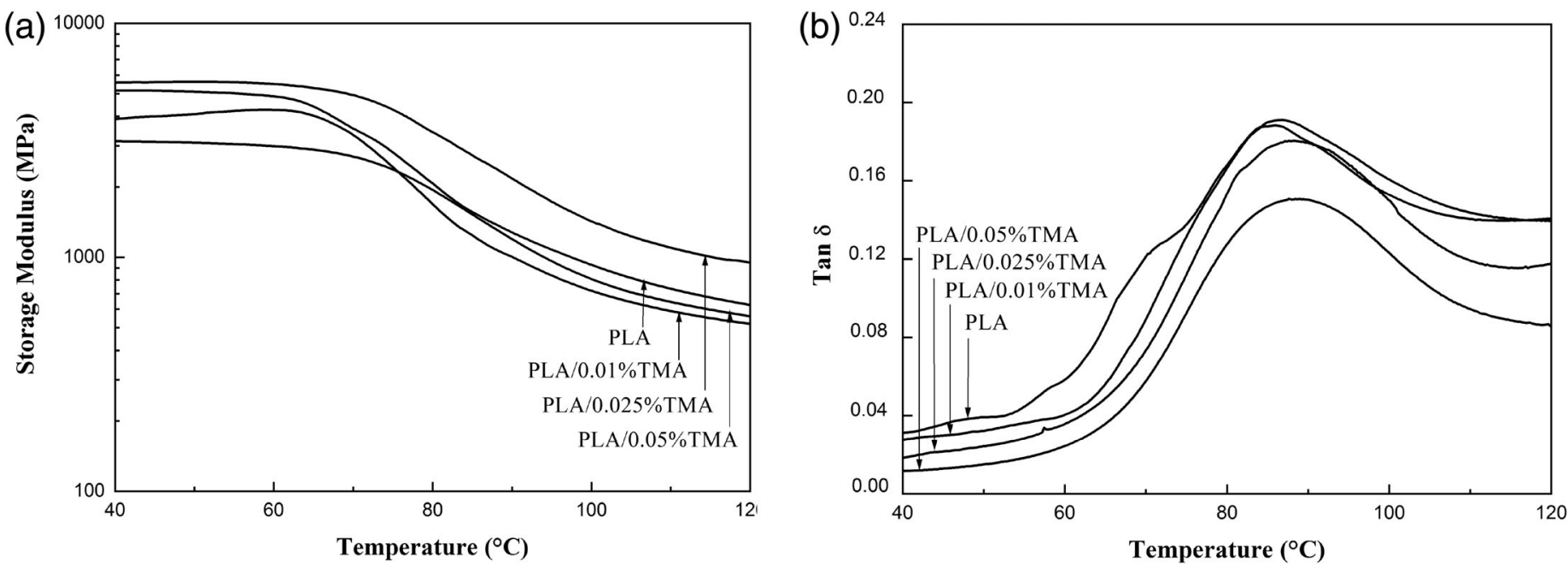

FIG. 4. Variation of: (a) the storage modulus and (b) $\tan \delta$ as a function of temperature for neat PLA and PLA/TMA.

\section{Structural Analysis of PLA/CAP and PLA/TMA}

To ascertain the reactions between PLA and the chain extenders and unveil eventual structural modifications of PLA, the ATR-FTIR spectra of neat PLA, PLA/CAP, and PLA/TMA have been recorded (Fig. 5). The ATR-IR spectrum of the neat PLA is given in Fig. 5a and shows an intense $\mathrm{C}=\mathrm{O}$ absorption band at $1,748 \mathrm{~cm}^{-1}$ corresponding to the stretching of the carbonyls in the ester groups, the stretching bands at $1,043-1,181 \mathrm{~cm}^{-1}$ of the $(\mathrm{C}-\mathrm{O})$ and $(-\mathrm{C}-\mathrm{O}-\mathrm{C}-)$ groups, and the bands at 1,455, 1,384, and $1,360 \mathrm{~cm}^{-1}$ due to the symmetric and asymmetric $(-\mathrm{C}-\mathrm{H})$ bending. The absorption bands at 957 and $872 \mathrm{~cm}^{-1}$ can be assigned to the $(-\mathrm{O}-\mathrm{H})$ and $(-\mathrm{C}-\mathrm{O}-\mathrm{C}-)$ vibrations of PLA [30].

The ATR-IR spectrum of CAP shows $\mathrm{C}-\mathrm{N}$ bands at 1,200 and $1,655 \mathrm{~cm}^{-1}$ due to the amide groups, some bands at $3,000-3,290 \mathrm{~cm}^{-1}$ related to the stretching vibrations of $(-\mathrm{N}-\mathrm{H})$ bonds, and the band at $690 \mathrm{~cm}^{-1}$ due to the out of plane vibration of $(-\mathrm{N}-\mathrm{H})$ bond $[15,28,31,32]$. Additionally, the bands at $2,854,2,928$, and $2,968 \mathrm{~cm}^{-1}$ are attributed to the symmetric and asymmetric stretching of $(-\mathrm{C}-\mathrm{H})$ bonds into $\left(-\mathrm{CH}_{2}-\right)$ and the ones at $1,485,1,439,1,417$, and $1,366 \mathrm{~cm}^{-1}$ correspond to $\left(-\mathrm{CH}_{2}-\right)$ bending. On the other hand, the ATR-IR spectrum of PLA/0.05 wt\% CAP reveals the presence of two $\mathrm{C}-\mathrm{H}$ bands at about 2,923 and $2,854 \mathrm{~cm}^{-1}$ owing to CAP, which confirms its presence in the PLA chains. Furthermore, a new band at $1,627 \mathrm{~cm}^{-1}$ due to $\mathrm{N}-\mathrm{H}$ stretching appears in PLA/0.05 wt\%

TABLE 1. Values of $T_{g}$ and maximum $\tan \delta$ obtained from DMTA plots for neat PLA, PLA/CAP, and PLA/TMA.

\begin{tabular}{lcc}
\hline Polymer & $T_{g}\left({ }^{\circ} \mathrm{C}\right)$ & Max $\tan \delta$ \\
\hline PLA & 86 & 0.19 \\
PLA/0.01 wt\% CAP & 88 & 0.21 \\
PLA/0.025 wt\% CAP & 88 & 0.18 \\
PLA/0.05 wt\% CAP & 82 & 0.19 \\
PLA/0.01 wt\% TMA & 87 & 0.19 \\
PLA/0.025 wt\% TMA & 89 & 0.15 \\
PLA/0.05 wt\% TMA & 79 & 0.14 \\
\hline
\end{tabular}

CAP, this suggests that the lactam cycle of CAP molecule has been disrupted and a new amide structure has been formed by reacting the amine end groups resulting from the CAP ring opening with the carboxyl groups of PLA (Fig. 2a). Therefore, the chain extension reaction between PLA and CAP is supported.

The ATR-IR spectrum of TMA in Fig. 5b shows a broadband ranging between 3,200 and $2,400 \mathrm{~cm}^{-1}$ due to hydrogen bond formation between hydroxyls owing to carboxylic groups of TMA. The most intense band at $1,700 \mathrm{~cm}^{-1}$ can be ascribed to the carbonyl groups of both the anhydride and the carboxylic acid (- $\mathrm{COOH}$ ) while the band at $1,410 \mathrm{~cm}^{-1}$ is related to the bending vibration of hydroxyl groups, and the band at $1,295 \mathrm{~cm}^{-1}$ is due to (- $\mathrm{CO}-\mathrm{O}-\mathrm{CO}-$ ) group. Furthermore, three bands attributable to $(-\mathrm{C}=\mathrm{C}-)$ of the aromatic ring are displayed between 1,500 and $1,575 \mathrm{~cm}^{-1}$ meanwhile a band at $775 \mathrm{~cm}^{-1}$ resulting from the deformation of $(-\mathrm{CH})$ groups in the aromatic ring of TMA is also evidenced. On the other hand, the ATR-IR spectrum of PLA/0.05 wt\% TMA reveals the presence of several bands between 1,500 and $1,542 \mathrm{~cm}^{-1}$ of the aromatic structure owing to TMA, which confirms its presence in the PLA chains. Furthermore, the new band detected at $1,616 \mathrm{~cm}^{-1}$ could be due to carbonyl groups resulting from the anhydride cycle opening in TMA [22]. This confirms the reaction between the hydroxyls in PLA and the anhydride groups of TMA and supports PLA extension, in agreement with the evidence of the torque measurements.

In order to provide further evidence on the chain extension of PLA by reaction with CAP and TMA, the wettability and surface energy of PLA/CAP and PLA/TMA were determined from contact angle measurements. The water $\left(\theta_{w}\right)$ and diiodomethane $\left(\theta_{i}\right)$ contact angles on neat PLA, PLA/CAP, and PLA/TMA are reported in Table 2. Generally, the hydrophilic or hydrophobic nature of a material surface could be estimated from the water contact angle value according to the "Berg limit" $\left(\theta=65^{\circ}\right)$, that is, surface materials with contact angles exceeding the limit value of $65^{\circ}$ are considered hydrophobic, while those with lower contact angles are considered hydrophilic [33]. The neat PLA surface has $\theta_{w}$ of $74^{\circ}$, in accordance with the values previously reported [34-37], and can be considered hydrophobic, in agreement with its low concentration of polar groups. In fact, the surface energy of the neat PLA is $36 \mathrm{~mJ} \mathrm{~m}{ }^{-2}$ and its dispersive component is 

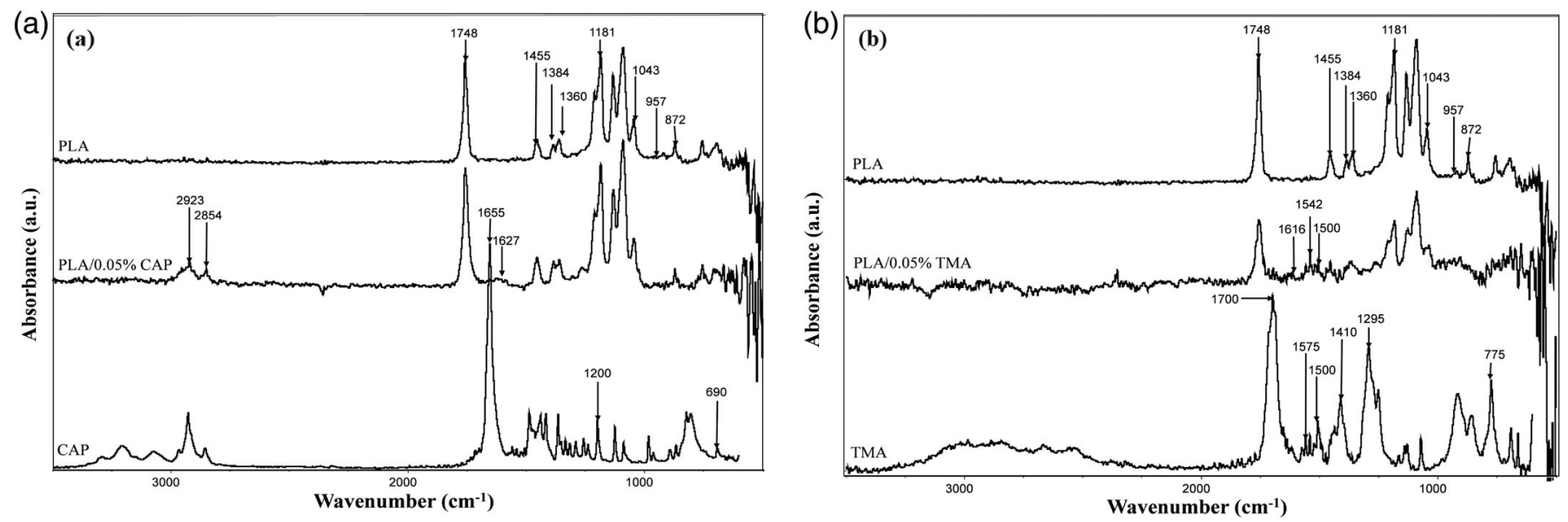

FIG. 5. ATR-FTIR spectra of: (a) CAP, neat PLA, and PLA/0.05\% CAP, (b) TMA, neat PLA, and PLA/0.05\% TMA.

$26 \mathrm{~mJ} \mathrm{~m}^{-2}$. The water contact angles of PLA/CAP are lower than for the neat PLA and they decrease by increasing the amount of CAP, indicating an increase in hydrophilicity. On the other hand, the diiodomethane contact angle values on PLA/CAP are lower than for the neat PLA and they do not vary with the amount of CAP in the PLA. As a consequence, the surface energies of PLA/CAP polymers are higher $\left(46-50 \mathrm{~mJ} \mathrm{~m}^{-2}\right)$ than the one of PLA, and the increase is mainly due to the enhancement of the polar component of the surface energy (the dispersive component does not vary in PLA/CAP formulations and is very similar to the one of the neat PLA), confirming that the chain extension of PLA is produced and higher hydrophilicity is imparted to the polymer by the polar groups of CAP. Similar evidence have been found by Jia et al. [34] who concluded that the contact angle values of PLA/graphene oxide (GO) composites were higher than that of PLA due to the polar nature of GO.

PLA/TMA formulations also show lower water and diiodomethane contact angle values than the neat PLA and their surface energies are higher than the one of the PLA. The increase in the surface energy is mainly due to the polar component, this confirming the increase in hydrophilicity of PLA and that the chain extension of PLA with TMA is produced. However, the trends in the contact angles and the surface energies of PLA/TMA formulations by varying the amount of TMA are opposite to the ones in PLA/CAP. Thus, the lowest contact angle values correspond to PLA/0.01 wt\% TMA, and they rise by increasing the amount of TMA. Similarly, the highest surface energy and polar component of the surface energy

TABLE 2. Contact angle values and surface free energy values for neat PLA, PLA/CAP, and PLA/TMA.

\begin{tabular}{lcccccc}
\hline & \multicolumn{2}{c}{ Contact angle $\left(^{\circ}\right)$} & & \multicolumn{3}{c}{ Surface energy $\left(\mathrm{mJ} \mathrm{m}^{-2}\right)$} \\
\cline { 2 - 3 } \cline { 6 - 7 } Polymer & $\theta_{w}$ & $\theta_{i}$ & & $\gamma_{s}$ & $\gamma_{s}{ }^{p}$ & $\gamma_{s}{ }^{d}$ \\
\hline PLA & $74 \pm 1$ & $53 \pm 1$ & & 36 & 10 & 26 \\
PLA/0.01 wt\% CAP & $61 \pm 1$ & $41 \pm 1$ & & 46 & 16 & 30 \\
PLA/0.025 wt\% CAP & $56 \pm 1$ & $39 \pm 1$ & & 48 & 19 & 30 \\
PLA/0.05 wt\% CAP & $54 \pm 1$ & $39 \pm 1$ & & 50 & 20 & 30 \\
PLA/0.01 wt\% TMA & $54 \pm 1$ & $37 \pm 1$ & & 51 & 20 & 31 \\
PLA/0.025 wt\% TMA & $59 \pm 1$ & $40 \pm 1$ & & 47 & 17 & 30 \\
PLA/0.05 wt\% TMA & $66 \pm 1$ & $50 \pm 1$ & & 40 & 14 & 26 \\
\hline
\end{tabular}

correspond to PLA/0.01 wt\% TMA, and the values for PLA/0.05 wt $\%$ TMA are close to the ones of the neat PLA. These findings suggest that the PLA surface gets hydrophilic character when both 0.01-0.05 wt \% CAP and 0.01 wt\% TMA chain extenders are incorporated since the $\theta_{w}$ values are lower than $65^{\circ}$. However, the hydrophilicity is lost by adding $0.025-0.05$ wt $\%$ TMA because of the more important reaction of the hydroxyl groups of PLA with the anhydride groups of TMA, which leads to the decrease of the hydrophilic character of the modified PLA. Also, the reaction of one TMA molecule with three chain ends of PLA against only two chain ends of PLA for one CAP molecule seems to affect notably the surface properties of the chain extended PLA.

\section{Crystallinity and Thermal Properties of PLA/CAP and PLA/TMA}

The thermal properties of the neat PLA, PLA/CAP, and PLA/TMA formulations were assessed by DSC and the corresponding thermograms are displayed in Fig. 6a-c. The second heating DSC thermogram of PLA shows the existence of the glass transition temperature at $61^{\circ} \mathrm{C}$ and the melting peaks at $166^{\circ} \mathrm{C}$ and $176^{\circ} \mathrm{C}$ with a total enthalpy of $62 \mathrm{~J} \mathrm{~g}^{-1}$. Furthermore, the cold crystallization peak of PLA appears at $112^{\circ} \mathrm{C}$ with a crystallization enthalpy of $59 \mathrm{~J} \mathrm{~g}^{-1}$. The bimodal melting behavior of PLA is typical of polyesters and semi-crystalline polymers [7, 38-40] and corresponds to the presence of two crystalline phases, namely the disordered and ordered pseudo-orthorhombic structures of various lamellar thicknesses and degree of perfection [8, 38, 41, 42].

After the addition of the chain extenders, the $T_{g}$ value of PLA decreases slightly to $58^{\circ} \mathrm{C}-60^{\circ} \mathrm{C}$ for PLA/CAP and $56^{\circ} \mathrm{C}-58^{\circ} \mathrm{C}$ for PLA/TMA, indicating some plasticizing effect induced by the longer PLA chains, which create more free volume allowing the segments mobility at lower temperatures as compared to the neat PLA. The first heating DSC thermograms show that the neat PLA does not undergo any crystallization contrary to both PLA/CAP and PLA/TMA formulations, which DSC thermograms display crystallization peaks ranging between $75^{\circ} \mathrm{C}$ and $105^{\circ} \mathrm{C}$. This evidence can be attributed to the fact that after processing, the neat PLA crystallized contrary to the chain extended PLA, which cooling prevents the longer chains from rearranging into more ordered structures and to undertake crystallization. Also, PLA/0.05 wt\% CAP presents a higher crystallization temperature $\left(92^{\circ} \mathrm{C}\right)$ than PLA/0.01 wt $\%$ CAP $\left(88^{\circ} \mathrm{C}\right)$. Similarly, PLA/0.05 wt 

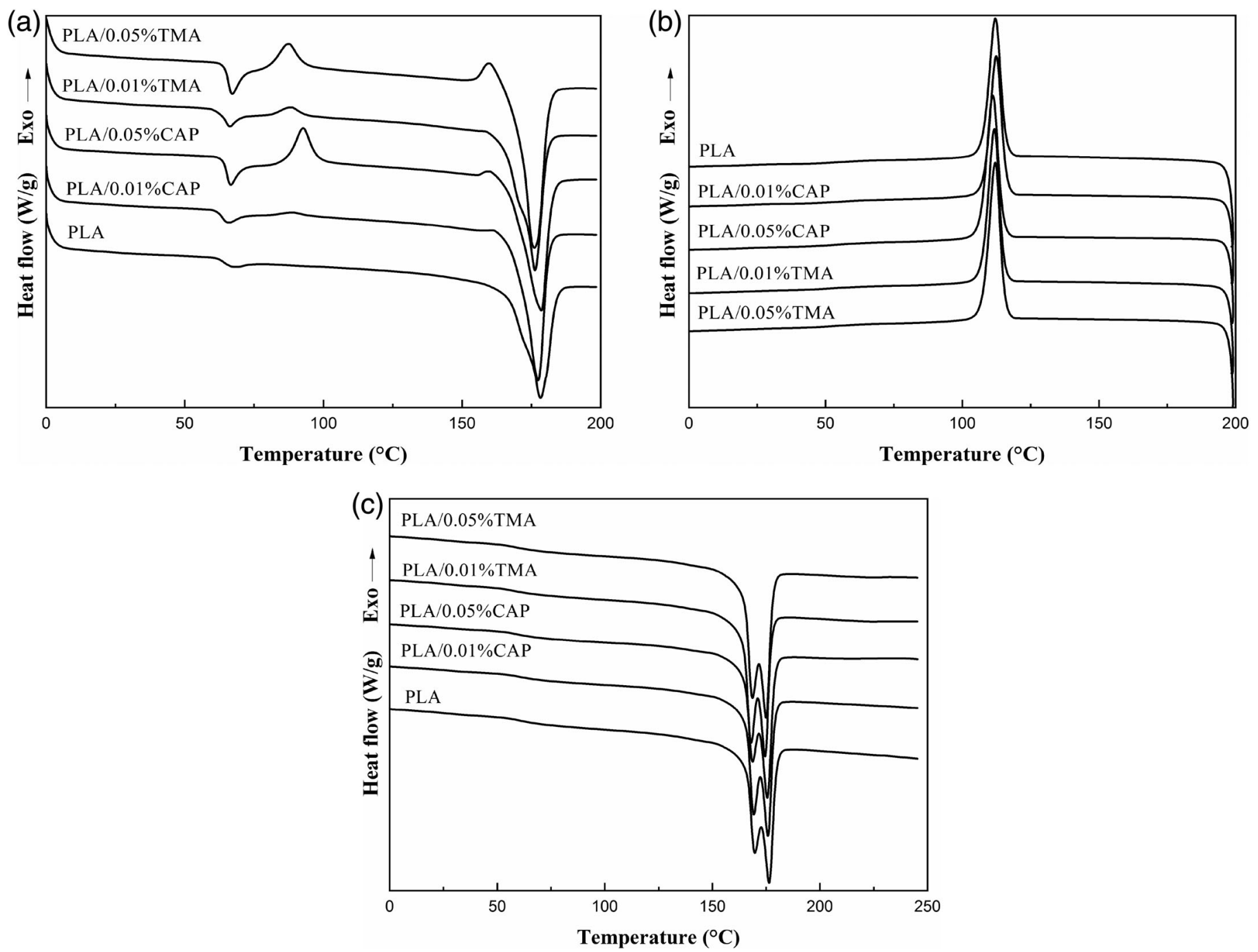

FIG. 6. DSC thermograms of neat PLA, PLA/CAP, and PLA/TMA: (a) first heating run, (b) cooling run, and (c) second heating run.

\% TMA exhibits a larger crystallization peak than PLA/0.01 wt\% TMA, that is, the higher the amount of the chain extender, the more important are the reaction rates. Since the upgraded PLA chains become longer and more complex than those in the neat PLA, their aptitude to crystallize is greatly depressed. On one hand, the chain extended PLA presents a higher fraction of free volume allowing more local polymer chains mobility, but on the other hand, due to its longer chains, the chain extended PLA presents a lower crystallization rate during the relatively higher cooling rate at the end of processing. This explains the results of the cooling DSC thermograms, which show the decrease in PLA/CAP and PLA/TMA crystallinity for CAP and TMA amounts of $0.05 \mathrm{wt} \%$. On the contrary, the second heating DSC thermograms suggest that due to the increased free volume fraction and the higher mobility of the local polymer chains in PLA/CAP and PLA/TMA, during the slow cooling run the polymer chains of the chain extended PLA may reorganize into more ordered structures, thus increasing the crystallinity (Table 3 ). Additionally, PLA/TMA

TABLE 3. Some thermal properties determined from the DSC thermograms of the neat PLA, PLA/CAP, and PLA/TMA.

\begin{tabular}{|c|c|c|c|c|c|c|c|c|}
\hline \multirow[b]{2}{*}{ Polymer } & \multicolumn{3}{|l|}{ Cooling } & \multicolumn{5}{|c|}{ Second heating } \\
\hline & $T_{c}\left({ }^{\circ} \mathrm{C}\right)$ & $\Delta H_{c}\left(\mathrm{~J} \mathrm{~g}^{-1}\right)$ & $\chi_{c}(\%)$ & $T_{g}\left({ }^{\circ} \mathrm{C}\right)$ & $T_{\mathrm{m} 1}\left({ }^{\circ} \mathrm{C}\right)$ & $T_{\mathrm{m} 2}\left({ }^{\circ} \mathrm{C}\right)$ & $\Delta H_{m}\left(\mathrm{~J} \mathrm{~g}^{-1}\right)$ & $\chi_{c}(\%)$ \\
\hline PLA & 112 & 59 & 63 & 61 & 166 & 176 & 62 & 67 \\
\hline PLA/0.01 wt $\%$ CAP & 112 & 59 & 63 & 60 & 169 & 176 & 63 & 68 \\
\hline PLA/0.05 wt $\%$ CAP & 111 & 58 & 62 & 58 & 169 & 176 & 63 & 68 \\
\hline PLA/0.01 wt $\%$ TMA & 112 & 59 & 63 & 56 & 168 & 174 & 65 & 70 \\
\hline PLA/0.05 wt $\%$ TMA & 112 & 56 & 60 & 58 & 169 & 175 & 65 & 70 \\
\hline
\end{tabular}




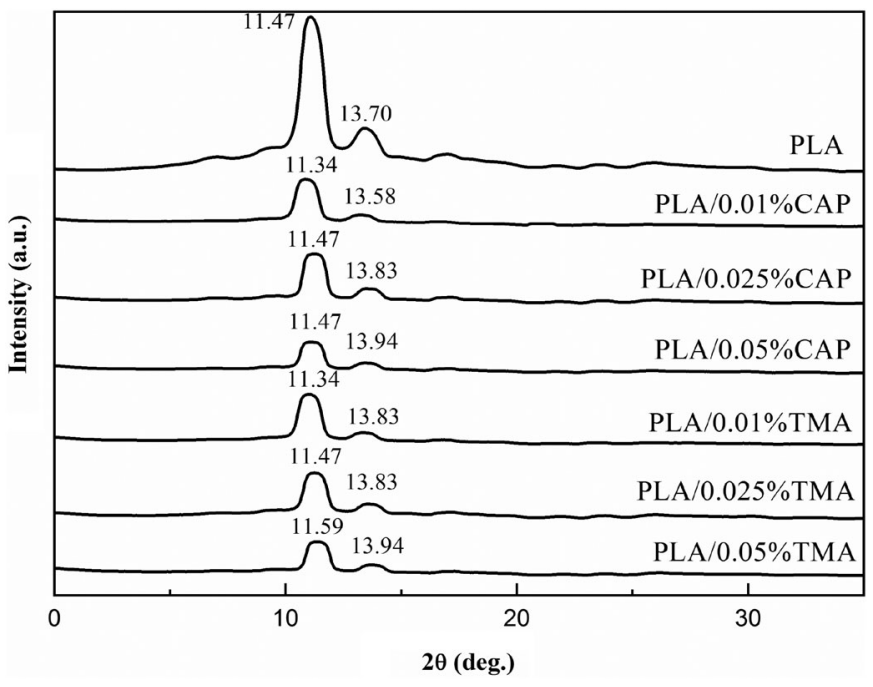

FIG. 7. XRD patterns of neat PLA, PLA/CAP, and PLA/TMA.

formulations present a crystallinity increase by $3 \%$ over that of the neat PLA due probably to the aromatic rings contained in the TMA structure, which contributes to generating a more important fraction of free volume and could also act as nucleating agents [22]. In this sense, Jaszkiewicz et al. [16] observed that the use of a chain extender increased the crystallinity due to the improvement in the crystallization rate; this resulted from its nucleating effect, which accelerated significantly the formation of crystalline structures. Inversely, Najafi et al. [40] concluded a decrease in the PLA crystallinity after chain extension using $1 \mathrm{wt} \%$ Joncryl due to the formation of a branched structure. Also, Liu et al. [18] reported that the PLA crystallization decreased as the epoxy chain extender concentration increased.

The XRD patterns of neat PLA and CAP and TMA chain extended PLAs are shown in Fig. 7. The XRD diffractogram of the neat PLA reveals a semi-crystalline material and shows an intense diffraction peak at $2 \theta=11.6^{\circ}$ corresponding to the (110) crystal lattice, and many other minor diffraction peaks at $14^{\circ}$, $17.3^{\circ}, 20^{\circ}, 22.4^{\circ}$, and $23.8^{\circ}$ related to the (103), (110/200), (203), (210), and (220) planes of PLA, respectively. All these reflections imply the coexistence of characteristic diffraction peaks for both stereocomplex and homocrystallites, which are consistent with trigonal and pseudo-orthorhombic structures of PLA [43-45]. Because the DSC thermograms seem to be consistent with a highly predominant pseudo-orthorhombic structure where the crystals adopt a helical conformation for the $\alpha$-form, it is suggested to be the more prevalent conformation of the neat PLA $[22,46]$.

No obvious diffraction peak shifting is observed in PLA/CAP and PLA/TMA with respect to the neat PLA, which implies that no polymorphic crystalline transition after chain extension is produced and that the way of molecular chains is packing into crystalline structures has not been affected. However, the intensities of the diffraction peaks of PLA/CAP and PLA/TMA are lower than in the neat PLA indicating lower crystallinity, in agreement with the findings in the DSC thermograms. In fact, the crystallite sizes of the polymers were determined from the diffraction peak at $2 \theta=11.65^{\circ}$ and a value of $15 \mathrm{~nm}$ is obtained for neat PLA but near $9 \mathrm{~nm}$ for both PLA/CAP and PLA/TMA (Table 4). The
TABLE 4. Main diffraction peaks and crystallite sizes for neat PLA, PLA/CAP, and PLA/TMA.

\begin{tabular}{|c|c|c|c|c|c|c|}
\hline \multirow[b]{2}{*}{ Chain extender (wt $\%)$} & \multicolumn{2}{|l|}{ PLA } & \multicolumn{2}{|c|}{ PLA/CAP } & \multicolumn{2}{|c|}{ PLA/TMA } \\
\hline & $2 \theta\left(^{\circ}\right)$ & $L(\mathrm{~nm})$ & $2 \theta\left(^{\circ}\right)$ & $L(\mathrm{~nm})$ & $2 \theta\left({ }^{\circ}\right)$ & $L(\mathrm{~nm})$ \\
\hline- & 11.60 & 15.0 & - & - & - & - \\
\hline 0.01 & - & - & 11.50 & 26.0 & 11.50 & 9.3 \\
\hline 0.025 & - & - & 11.60 & 9.6 & 11.60 & 9.1 \\
\hline 0.05 & - & - & 11.60 & 9.5 & 11.60 & 9.7 \\
\hline
\end{tabular}

X-ray diffraction experiments.

decline in the PLA crystals size could be associated to the fact that the chain extender acts as a nucleating agent which favors crystallization. The favored crystallization is particularly promoted in PLA/TMA because the rigid structure of the aromatic rings facilitates the establishment of a more structural order in the PLA chains.

TGA experiments were carried out to investigate the effect of the addition of TMA and CAP chain extenders on the thermal stability of PLA. Figure 8a and b depicts the variations of the weight and the derivative of the weight as a function of the temperature for PLA/CAP and PLA/TMA, respectively. The thermal decomposition of the neat PLA, PLA/CAP, and PLA/TMA occurs in a single step. The weight loss of the neat PLA starts at $280^{\circ} \mathrm{C}$ and shows a maximum at $351^{\circ} \mathrm{C}$, finishing at $361^{\circ} \mathrm{C}$. The rate of weight loss is about $2.3 \% \mathrm{~min}^{-1}$, and the $T_{5 \%}$ and $T_{50 \%}$ values are $305^{\circ} \mathrm{C}$ and $344^{\circ} \mathrm{C}$, respectively. The addition of both chain extenders improves the thermal stability of PLA (Table 5). In the case of PLA/CAP formulations, the value of $T_{\mathrm{d} 0}$ increases by $10^{\circ} \mathrm{C}-20^{\circ} \mathrm{C}$ relative to the neat PLA, whereas the $T_{5 \%}$ value increases by $10^{\circ} \mathrm{C}-14^{\circ} \mathrm{C}$. The same trend in the thermal stability is observed in PLA/TMA formulations, an increase in $T_{\mathrm{d} 0}$ and $T_{5 \%}$ values of $19^{\circ} \mathrm{C}$ and $12^{\circ} \mathrm{C}$, respectively, relative to the neat PLA is obtained. Also, the values of $T_{50 \%}, T_{\mathrm{dmax}}$, and $T_{\mathrm{df}}$ for PLA/CAP and PLA/TMA are higher than those of the neat PLA by an average value of $4^{\circ} \mathrm{C}$.

The improvement of the thermal stability of the chain extended PLA might be due to the longer polymer chains and to the reduced number of chains ends [2]. Khankrua et al. [15] stated that the improvement in the PLA thermal stability could result from the incorporation of functional groups owing to chain extender molecules that could react with the hydroxyl or carboxyl groups of PLA. This leads to a decrease in the number of active sites in the chain ends and delays the PLA degradation by preventing the de-polymerization process by backbiting reactions.

\section{Impact Resistance and Morphology of PLA/CAP and PLA/TMA}

One major drawback of PLA is its inherent brittleness. Several authors $[15,18]$ evidenced the beneficial effect induced on the PLA resilience when chain extenders are added. Also, it is well known that the mechanical properties of a polymer are governed by the crystallinity, the structure, and the molecular weight, among other parameters [47]. A high molecular weight increases the impact resistance, the tensile strength, and elastic modulus of the polymer, because of a higher degree of entanglement. So in order to cause the polymer failure, more bonds must be ruptured, which implies more important energy absorption. Figure 9 

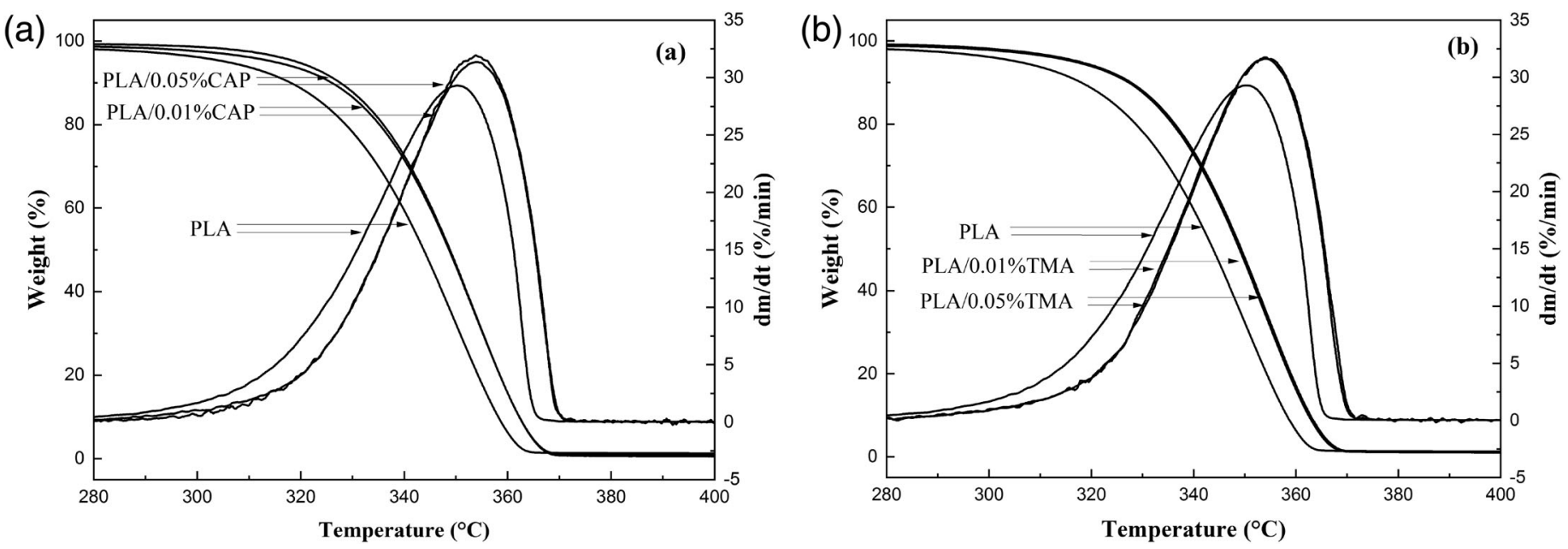

FIG. 8. TG and DTG thermograms of: (a) PLA/CAP and (b) PLA/TMA.

displays the variation of the Izod impact resistance for PLA/CAP and PLA/TMA as a function of the amount of chain extender. The impact strength of PLA is $13 \mathrm{~kJ} \mathrm{~m}^{-2}$ and increases by adding $0.01 \mathrm{wt} \%$ both chain extenders to $17-18 \mathrm{~kJ} \mathrm{~m}^{-2}$ in PLA/0.01 wt $\%$ CAP and PLA/0.01 wt\% TMA (improvements by 31\%-38\%). This substantial increase in the impact strength can be ascribed to the increased PLA molecular weight $[15,18]$, as also stated from the enhancement of the storage modulus at low temperature in the chain extended PLA (Figs. 3 and Fig. 4). Indeed, the amelioration in the impact strength of PLA could be explained by the increase in the free volume, thus generating a more favorable energy dissipating process. Also, it is thought that as the PLA chains become longer, more chains entanglement sites are created, thus favoring further anchoring between them, which further increases the PLA resistance to impact. However, the impact resistance of PLA/0.05 wt\% CAP and PLA/0.05 wt\% TMA decreases with respect to the one of the formulations with $0.01 \mathrm{wt} \%$ chain extender, but it is still higher than that of the neat PLA. This seems to be because more the chain extension process advances, the lower is the polymer chain mobility due to their tighter packing and a reduction in the free volume is produced [18].

The morphology of the fractured samples after the impact test was assessed by SEM and the obtained micrographs are given in Fig. 10. The SEM micrograph of the neat PLA (Fig. 10) corresponds to the typical morphology of a brittle material because the fractured surface is uneven and shows many irregular and short fracture paths generated from the rapid merging of the existing

TABLE 5. TGA results for neat PLA, PLA/CAP, and PLA/TMA.

\begin{tabular}{|c|c|c|c|c|c|}
\hline \multirow[b]{2}{*}{ Parameter } & \multirow[b]{2}{*}{ PLA } & \multicolumn{2}{|c|}{$\mathrm{CAP}(\mathrm{wt} \%)$} & \multicolumn{2}{|c|}{ TMA (wt $\%)$} \\
\hline & & 0.01 & 0.05 & 0.01 & 0.05 \\
\hline$T_{\mathrm{d} 0}\left({ }^{\circ} \mathrm{C}\right)$ & 280 & 290 & 300 & 293 & 299 \\
\hline$T_{5 \%}\left({ }^{\circ} \mathrm{C}\right)$ & 305 & 315 & 319 & 317 & 317 \\
\hline$T_{50 \%}\left({ }^{\circ} \mathrm{C}\right)$ & 344 & 348 & 348 & 349 & 349 \\
\hline$T_{\mathrm{dmax}}\left({ }^{\circ} \mathrm{C}\right)$ & 351 & 354 & 354 & 354 & 354 \\
\hline$T_{\mathrm{df}}\left({ }^{\circ} \mathrm{C}\right)$ & 361 & 365 & 364 & 365 & 365 \\
\hline Weight loss at $T_{\mathrm{dmax}}(\%)$ & 31 & 34 & 34 & 35 & 37 \\
\hline$V_{\mathrm{d}}\left(\% \min ^{-1}\right)$ & 2.3 & 2.3 & 2.3 & 2.2 & 2.1 \\
\hline
\end{tabular}

microcracks. These features attest that the crack initiation for neat PLA is most likely due to material discontinuities as evidenced by the presence of several microcavities and that the propagation easily ensued to the polymer drastic rupture with relatively low energy absorption. According to Tanniru et al. [48] the crack initiation in a polymer was ascribed to the formation of microcavities and inhomogeneities inside the material. In opposite, Jaszkiewicz et al. [16] conferred the crack initiation to material discontinuities caused by either contamination resulting from processing or larger accumulations of branched polymer chains.

The SEM micrographs of PLA/CAP formulations with 0.01 and $0.05 \mathrm{wt} \%$ of CAP (Fig. 10b and c) display totally different fractured surfaces than in the neat PLA due to the change in the polymer microstructure after the incorporation of the chain extender. The SEM micrograph of PLA/0.01 wt\% CAP exhibits a smoother surface with a significant decline in the microcracks density, which could be originated from the depressed discontinuity inside the sample as a result of the

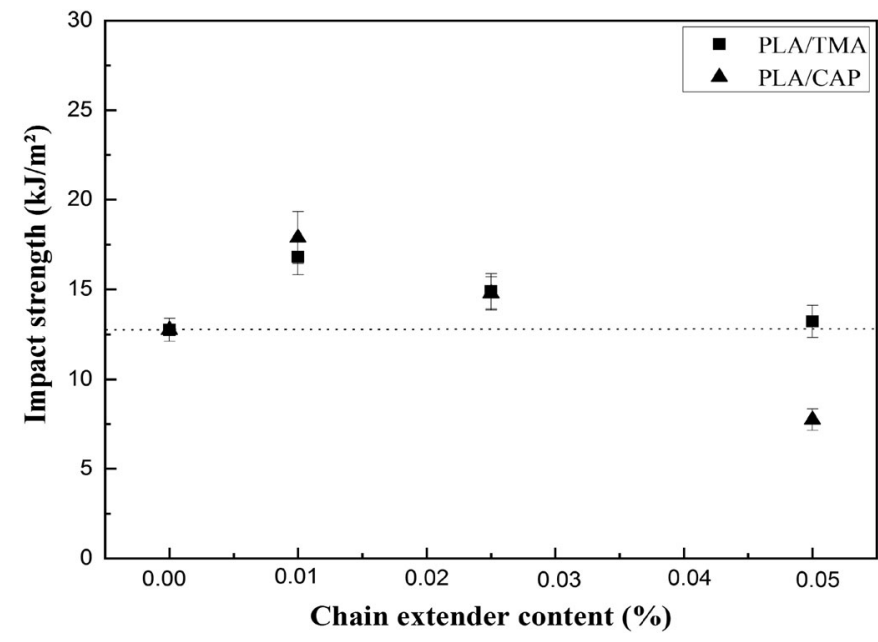

FIG. 9. Variation of Izod impact strength for PLA/CAP and PLA/TMA as a function of the amount of chain extender. The dotted line corresponds to the Izod impact strength of the neat PLA. 

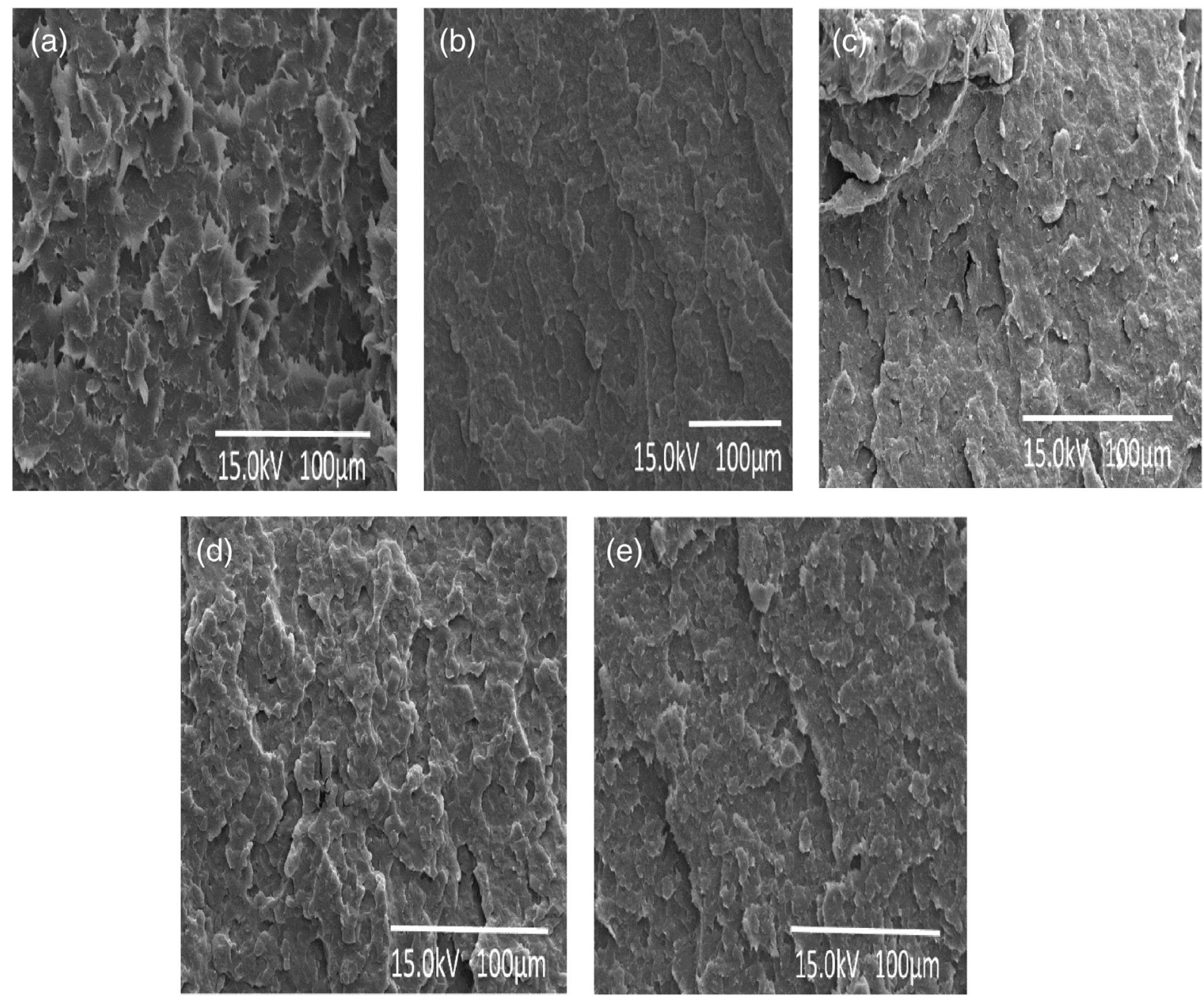

FIG. 10. SEM micrographs of: (a) neat PLA, (b) PLA/0.01\% CAP, (c) PLA/0.05\% CAP, (d) PLA/0.01\% TMA, and (e) PLA/0.05\% TMA.

PLA chain extension. Conversely, the fracture surface of PLA/0.05 wt \% CAP shows a stratified topography presenting many tiny and large cracks that reveal more regular and smoother edges as compared to the sharper and irregular ones perceived for neat PLA.

The SEM micrographs of the fractured PLA/TMA surfaces (Fig. 10 and 10) show that the addition of TMA into PLA results also in a laminated topography featured by a further decrease in the number of microcracks and discontinuities relatively to the neat PLA. However, the fracture surfaces are relatively rougher than those of PLA/CAP formulations and display a higher density of cracks and microcracks that are unevenly deviated in random directions. The roughness of the fracture surface of PLA/TMA could be attributed to the crack deflection and creation of additional surface area or new cracks during the material solicitation. These might suggest that a part of the applied energy is consumed by processes implicated into the creation of new fracture surfaces, which would result in a higher impact resistance. Additionally, the cracks edges for PLA/0.05 wt\% TMA seem to be less sharp and propagate through longer and straight lines along the sample thus indicating a less stiff material.

\section{CONCLUSIONS}

The assessment of the torque at stability for PLA/TMA and PLA/CAP showed an obvious increase assigned to the increment in the PLA molecular weight due to chain extension processes. Even though ATR-IR spectra provided only the confirmation of the insertion of CAP and TMA moieties into the PLA chains by the appearance of new bands, the contact angle measurement results afforded several substantial supplementary evidence corroborating the PLA chain extension. In this sense, the reaction of the anhydrides of TMA with the hydroxyl groups of PLA has been proved through the notable increase in the water contact angle and the decrease in the polar component of the surface free energy, thus emphasizing the decrement in hydroxyl groups concentration at the surface. However, in the case of PLA/CAP, the increased hydrophilic character of PLA was assigned simultaneously to the reaction of CAP molecules with a relatively lesser amount of PLA hydroxyls as compared to TMA and the increased concentration of the polar groups provided by CAP moieties at the surface of PLA/CAP samples.

Additionally, as a result of the PLA chain extension by using both TMA and CAP and the subsequent increase in the polymer viscosity, significant improvements have been achieved on both 
the thermal stability and impact resistance. The amelioration in the PLA strength is interpreted by the transition of the fracture morphology to a stratified structure with a lesser density of microvoids and a higher aptitude to energy dissipation via the creation of novel fracture planes.

Furthermore, the increased ability to crystallization of PLA in PLA/CAP and PLA/TMA formulations might result from the possible nucleating effect induced by the chain extender moieties inserted into the PLA chains and the increased mobility of these as confirmed by their lower glass transition temperature values.

\section{References}

1. K. Suthapakti, R. Molloy, W. Punyodom, K. Nalampang, T. Leejarkpai, P.D. Topham, and B.J. Tighe, J. Polym. Environ., 26, 1818 (2017).

2. N. Najafi, M.C. Heuzey, P.J. Carreau, and P.M. Wood-Adams, Polym. Degrad. Stab., 97, 554 (2012).

3. J. Ren, Biodegradable Poly(lactic acid): Synthesis, Modification, Processing and Applications, Springer, Shanghai, China (2010).

4. R. Siakeng, M. Jawaid, H. Ariffin, S.M. Sapuan, M. Asim, and N. Saba, Polym. Compos., 40, 446 (2018).

5. Y. Wang, S.M. Chiao, T.F. Hung, and S.Y. Yang, J. Appl. Polym. Sci., 125, E402 (2012).

6. J.W. Rhim, S.I. Hong, and C.S. Ha, LWT - Food Sci. Technol., 42, 612 (2009).

7. L.C. Arruda, M. Magaton, R.E.S. Bretas, and M.M. Ueki, Polym. Test., 43, 27 (2015)

8. N. Chelghoum, M. Guessoum, M. Fois, and N. Haddaoui, J. Polym. Environ., 26, 342 (2017).

9. Z. Samouh, K. Molnar, F. Boussu, O. Cherkaoui, and R. El Moznine, Polym. Adv. Techol., 29, 1 (2018).

10. C. Lui, S. Lin, C. Zhou, and W. Yu, Polymer, 54, 310 (2013).

11. M. Maiza, M.T. Benaniba, and V. Massardier-Nageotte, J. Polym. Eng., 36, 371 (2015).

12. A. Jaszkiewicz, A.K. Bledzki, A. Duda, A. Galeski, and P. Franciszczak, Macromol. Mater. Eng., 299, 307 (2014).

13. D. Garlotta, J. Polym. Environ., 9, 63 (2001).

14. V. Frenz and D. Scherzer, Multifunctional Polymers as Chain Extenders and Compatibilizers for Polycondensates and Biopolymers, Annual Technical Conference of the Society of Plastics Engineers (ANTEC), Milwaukee, Wisconsin, USA (2008).

15. R. Khankrua, S. Pivsa-Art, H. Hiroyuki, and S. Suttiruengwong, Polym. Degrad. Stab., 108, 232 (2014).

16. A. Jaszkiewicz, A.K. Bledzki, R. van der Meer, P. Franciszczak, and A. Meljon, Polym. Bull., 71, 1675 (2014).

17. J. Scheirs, Modern Polyesters: Chemistry and Technology of Polyesters and Copolyesters, Wiley, Chichester, England (2003).

18. Z.Y. Liu, Y.X. Weng, Z.G. Huang, L. Wang, D. Qiu, and S. X. Shao, Adv. Mater. Sci. Eng., 2, 1 (2018).

19. S.R. Rathi, E.B. Coughlin, S.L. Hsu, C.S. Golub, G.H. Ling, and M.J. Tzivanis, Polymers, 6, 1232 (2014).

20. F. Iñiguez-Franco, R. Auras, J. Ahmed, S. Selke, M. Rubino, K. Dolan, and H. Soto-Valdez, Polym. Test., 67, 190 (2018).

21. N. Najafi, M.C. Heuzey, and P.J. Carreau, Compos. Sci. Technol., 72, 608 (2012).
22. C.A. Ramirez-Herrera, A.I. Flores-Vela, A.M. Torres-Huerta, M. A. Dominguez-Crespo, and D. Palma-Ramirez, J. Mater. Sci., 53, 10846 (2018).

23. M. Buccella, A. Dorigato, E. Pasqualini, M. Caldara, and L. Fambri, Polym. Eng. Sci., 54, 158 (2014).

24. L. Gouissem, A. Douibi, and D. Benachour, Polym. Sci. Ser. A, 56, 844 (2014).

25. X. Meng, G. Shi, C. Wu, W. Chen, Z. Xin, Y. Shi, and Y. Sheng, Polym. Degrad. Stab., 124, 112 (2016).

26. M. Xanthos, U. Yilmazer, S.K. Dey, and J. Quintans, Polym. Eng. Sci., 40, 554 (2000).

27. F. Awaja, F. Daver, E. Kosior, and F. Cser, J. Therm. Anal. Calorim., 78, 865 (2004).

28. V.S. Giita Silverajah, N.A. Ibrahim, N. Zainuddin, W.M.Z. W. Yunus, and H. Abu Hassan, Macromolecules, 17, 11729 (2012).

29. S.O. Han, M. Karevan, I.N. Sim, M.D.A. Bhuiyan, Y.H. Jang, J. Ghaffar, and K. Kalaitzidou, Int. J. Polym. Sci., 8, 1 (2012).

30. A.M. Torres-Huerta, D. Del Angel-López, M.A. DomínguezCrespo, D. Palma-Ramírez, M.E. Perales-Castro, and A. FloresVela, Polym. Plast. Techol. Eng., 55, 672 (2016).

31. A. Basterretxe, E. Gabirondo, A. Sanchez-Sanchez, A. Etxeberria, O. Coulembier, D. Mecerreyes, and H. Sardon, Eur. Polym. J., 95, 650 (2017).

32. S.P. Rwei, P. Ranganathan, and Y.H. Lee, Polymers, 11, 472 (2019).

33. E.A. Vogler, Adv. Colloid Interface Sci., 74, 69 (1998).

34. S. Jia, D. Yu, Y. Zhu, Z. Wang, L. Chen, and L. Fu, Polymers, 9, 528 (2017).

35. M. Navarro, E. Engel, J.A. Planell, I. Amaral, M. Barbosa, and M.P. Ginebra, J. Biomed. Mater. Res., Part A, 85A, 477 (2007).

36. S. Chitrattha and T. Phaechamud, Adv. Mater. Res., 528, 140 (2012).

37. H. Mario, F.J. Rodríguez-Gonzalez, and Y. Perera-Mercado, Macromol. Symp., 374, 1600130 (2017).

38. W. Dong, B. Zou, Y. Yan, P. Ma, and M. Chen, Int. J. Mol. Sci., 14, 20189 (2013).

39. P.M. Ma, R.Y. Wang, S.F. Wang, Y. Zhang, Y.X. Zhang, and D. Hristova, J. Appl. Polym. Sci., 108, 1770 (2008).

40. N. Najafi, M.C. Heuzey, and P.J. Carreau, Polym. Sci. Eng., 53, 1053 (2013).

41. N. Medjdoub, M. Guessoum, and M. Fois, J. Adhes. Sci. Technol., 31, 787 (2016).

42. F. Bouzidi, M. Guessoum, M. Fois, and N. Haddaoui, J. Adhes. Sci. Technol., 32, 496 (2017).

43. Y. Baimark and S. Kittipoom, Polymers, 10, 1218 (2018).

44. L. Cui, Y. Wang, Y. Guo, Y. Liu, J. Zhao, C. Zhang, and P. Zhu, Adv. Polym. Technol., 37, 962 (2016).

45. J.Z. Xu, Y. Li, Y.K. Li, Y.W. Chen, R. Wang, G. Liu, S.M. Liu, H.W. Ni, and Z.M. Li, Polymer, 140, 179 (2018).

46. D. Brizzolara, H.J. Cantow, K. Diederichs, E. Keller, and A. J. Domb, Macromolecules, 29, 191 (1996).

47. L. Shen, I.Y. Phang, L. Chen, T. Liu, and K. Zeng, Polymer, 45, 3341 (2004).

48. M. Tanniru, Q. Yuan, and R.D.K. Misra, Polymer, 47, 2133 (2006). 